\title{
GRANULOMA INGUINALE
}

\author{
BY \\ P. A. CLEARKIN \\ From the Caribbean Medical Centre, Port of Spain, Trinidad, and The Institute of Pathology, \\ Queen's University, Belfast
}

Granuloma inguinale (lymphogranuloma inguinale, ulcerating granuloma of the pudenda, sclerosing granuloma, granuloma venereum), though first described in British possessions over fifty years ago, has received little attention from English workers; and as practically all recent observations have been made in the United States of America it might be inferred that the disease is uncommon in British possessions. This would be an erroneous deduction for it is widespread throughout the British West Indian islands. The writer saw several hundred cases in the course of a few years, and the following account is based on his observations and study of the disease there.

The terminology of the ulcerative conditions in the genital region has been the subject of much confusion, and it may be well to explain that granuloma inguinale refers to the disease associated with the presence of Donovan bodies in the lesions and a negative Frei reaction. It should not be confused with lymphopathia venereum (lymphogranuloma venereum, climatic bubo) which is caused by a filter-passing virus and gives a positive Frei reaction.

\section{Review of the Literature}

McLeod (1882) appears to have been the first to direct attention to this condition, under the title of "Serpiginous Ulcer" in Madras. Ozzard and Neal (1893) described cases of " a peculiar form of ulceration common in British Guiana," but they appear to have been a variety of ulcerative conditions of the genital region including granuloma inguinale. To Conyers and Daniels (1896) belong the credit of first separating granuloma inguinale from other similar or somewhat similar lesions in the genital region under the heading "The Lupoid Form of the so-called Groin Ulceration." They said this was only one of several forms of groin ulceration present in the colony, its main characteristics being "its chronicity, its spread peripherally, and by preference along the folds of the skin, its nodular edge, the absence of suppuration or caseation except as a very occasional factor and the tendeñcy to deep scar formation with no tendency to glandular involvement or serious impairment of the general health." They furthermore stated that it is not accompanied by much pain and the disease is not, strictly speaking, an ulceration. An excellent clinical description of granuloma inguinale. Galloway (1897), under the title " Ulcerating Granuloma of the Pudenda," gave a detailed description of the disease from information furnished by Daniels and from his own observations on a case seen in London in a native of the West Indies, and he added an excellent account of the histological changes. Fowler (1899) referred to the ulcerating granulomata so common in Demerara and described a case in which the bladder had been penetrated.

The first reference to the disease by Donovan (1905) is to be found in a general article entitled " Medical cases from Madras General Hospital." * In it an account is given of bodies seen in epithelial cells of the stratum malpighii in the deeper part of the growth in cases of ulcerating granuloma of the pudenda. No illustrations are given, and it is doubtful if these bodies are the same as the presentday Donovan bodies. They are described as being present in the epithelial cells, but the organisms now known as Donovan bodies are found in mononuclear cells in the exudate in the papillary processes. Donovan described the bodies as "epithelial cell parasites belonging to the gregarine order of sporozoa." Sequeira (1908) showed, in London, a negro from Antigua with a penile ulcer and a large granulomatous tumour at the angle of his mouth. Daniels saw this case and agreed that it resembled "the ulcerative or rather sclerosing granuloma of the pudenda" common in the West Indies. A good colour photograph of the case is shown by Sequeira, and it resembles what is now known as granuloma inguinale. Carter (1910) in

* Some of the references in the literature are incorrect. They refer to Donovan (1904), which is a reference to Leishman-Donovan bodies in Kala-Azar. 
an account of six cases of "ulcerating granuloma of the pudenda" seen in India, says that the views held by most observers regarding the ætiology are entirely wrong, and describes large mononuclear cells filled with bodies " resembling the gregariform stage of herpetamonas or crithidia " similar to those seen in sections from oriental sore. His description and accompanying sketches show that the bodies resemble those now known as Donovan bodies. Daniels (1910), in a letter commenting on Carter's paper, said he had re-examined his material from British Guiana but was unable to find bodies resembling those described by Carter.

The first cases in the United States of America were reported by Grindon (1913) under the title "Granuloma Inguinale Tropicum." He failed to confirm Carter's findings, but as he does not give an adequate description of his cases it is possible that they were of a different nature. Lynch (1921) isolated Gram-negative capsulated bacilli which he claimed were Donovan bodies, and during the 1920 decade many cases were reported from America and claims were made that Donovan bodies or other organisms responsible for the disease had been cultured. A long and detailed description is given by Goldzieher and Peck (1926) under the title "Das venerische Granulom." They isolated an intracellular capsulated bacillus which they called the granulom bacillus. Castellani and Mendelson (1929) cultured a capsulated bacillus which they described as $B$. lactis arogenes, genus encapsulatus, Castellani and Chalmers. Pund and Greenblatt (1937) described a large mononuclear cell filled with intracytoplasmic cysts containing deeply staining bodies which they claimed was consistently present in the exudate. To this cell they attached the term " pathognomonic cell." D'Aunoy and Von Haam (1937) observed Donovan bodies in practically all tissue sections from granuloma inguinale stained with Wright's stain. Many workers cultured organisms in ordinary laboratory media which they claimed were Donovan bodies, but their claims were not confirmed. Anderson (1943) reported successful cultivation in the yolk sac of chick embryos but was unable to obtain growth on ordinary laboratory media. Various other workers confirmed her claim, and recently Rake and Oskay (1948) cultivated the organisms on laboratory media after isolation in chick embryo sac. The organisms are said to be pleomorphic Gram-negative bacilli with characteristic polar granules. Rake (1948) further claims that the organisms thus isolated are genuine Donovan bodies and that they are antigenically related to several members of "the tribe of Escherichae."

Some workers claim to have transmitted the disease to laboratory animals but the great majority deny that this can be done. Dienst, Greenblatt, and Sanderson (1938) and others claim to have transmitted it to human volunteers by means of suspensions containing Donovan bodies but no other organisms, and to have recovered Donovan bodies from the lesions thus produced.

\section{Characteristics of Granuloma Inguinale}

Geographical Distribution.-Granuloma inguinale was originally considered a tropical disease but it has now been recognized in many temperate climates. D'Aunoy and others (1938) confirm the statement of earlier observers that it appeared first in the great seaports of the United States and travelled inland along the large waterways. No reports of indigenous cases in the British Islands have appeared in the literature, but two have recently been observed in Belfast, Northern Ireland (Clearkin and Flewett, 1948).

Aetiology.-It seems to be established that the causative organism is the Donovan body, though its nature is still in doubt. Greenblatt (1943) thinks that it is a strict tissue parasite of man.

Incubation Period.-The incubation period is doubtful. In the experimental disease in human volunteers the classical appearance did not develop until the fiftieth day.

Epidemiology.-Granuloma inguinale is generally considered a venereal disease, though some dissent from this opinion. In Trinidad it is practically confined to the most promiscuous section of the population and is looked upon as a venereal disease. Although cases have been recorded in, young children and in an old man of 94 , the majority occur during the age of greatest sexual activity and among sexually promiscuous people. Many undoubted examples of non-venereal infection have been reported, but this cannot be used as an argument against its venereal origin any more than the occurrence of extra-genital cases of syphilis can be used as an argument against its venereal origin.

Age Incidence.-As has been said, the incidence is greatest during the period of greatest sexual activity. This is shown by the Table from the Caribbean Medical Centre. Similar figures have been given by other observers.

Racial Incidence. $\rightarrow$ Africans are said to be more susceptible to the disease than others. The incidence certainly appears to be greater in Africans but this does not prove a racial susceptibility. Racial differences may be explained by social conditions and sex habits. In the Caribbean 
TABLB

CASES OBSERVED IN THE CARIBbEAN MEDICAL CENTRE

\begin{tabular}{|c|c|c|c|c|}
\hline \multicolumn{4}{|c|}{ Age group } & Cases \\
\hline $\begin{array}{l}20 \text { years and under } \\
21 \text { to } 30 \\
31 \text { to } 40 \\
41 \text { to } 50 \text {.. } \\
\text { over } 50 \text { years }\end{array}$ & $\begin{array}{l}\cdots \\
\ldots \\
\cdots \\
\ldots\end{array}$ & $\begin{array}{l}\cdots \\
\cdots \\
\cdots \\
\cdots\end{array}$ & $\begin{array}{l}\cdots \\
\cdots \\
\cdots \\
\ldots\end{array}$ & $\begin{array}{l}21 \\
77 \\
48 \\
27 \\
15\end{array}$ \\
\hline
\end{tabular}

Medical Centre the majority of cases seen were in persons of African descent, but as Africans form the largest racial group in the island and moreover form the bulk of that section of the population living under insanitary conditions, sexually promiscuous, and exposed to repeated opportunities for infection, it is not surprising that the majority of those seen suffering from granuloma inguinale belong to that racial group. The incidence of all venereal diseases is greatest in this group ; of 60,556 cases of venereal disease seen at the Centre, 39,000 were in Africans.

In the United States most of the cases are in coloured people, but, as the living conditions and sex habits of the coloured people are similar to those of the coloured people in Trinidad and the incidence of venereal disease in the coloured people in the United States is much higher than in the white races, the same argument applies. Until much better evidence is furnished it would be unwise to accept the statement that the African race is peculiarly susceptible to granuloma inguinale.

Clinical Description.-Early lesions are rarely seen, as they are painless and cause little discomfort. Medical assistance is therefore not requested until a large area is affected or secondary infection .with accompanying pain and discomfort drive the patient to the doctor.

The earliest lesion seen in Trinidad was of about four weeks' duration (Fig. 5) and was described as having started as a small pimple which burst and formed a sore which gradually increased in size. One of the Belfast patients said a small lump appeared on the shaft of the penis which persisted for about a year, then burst and formed a sore which spread rapidly to the scrotum and lower part of the abdomen.

When it was first seen, the lesion in the Trinidad case was an oval, raised plaque of granulation tissue about half an inch long by one quarter of an inch across with smooth elevated edges sharply demarcated from the surrounding skin which was not inflamed. The edges were not undermined; there was no regional lymphadenitis and only a slight sero-sanguineous discharge. The lesion was almost painless, only slightly tender, and apparently did not interfere with the patient's sexual activities as he retained connexion with his " girl friend." His general health was unaffected; he was well nourished, fit, and well.

In the male the early or primary lesion is usually seen on the penis ; in the female it usually appears on the labiæ. Inguinal lesions are usually secondary to lesions on the penis or labiæ. Greenblatt and others claim that the Donovan bodies travel by way of the lymphatics to the inguinal lymph nodes, causing little or no disturbance on the way, and that they localize there and eventually reach the overlying skin, reproducing, the granuloma. It is certainly the case that histories are not infrequently obtained that a sore appeared first on the penis and that later, quite independently, another sore appeared in the inguinal region (Fig. 2).

The primary sore on the penis may spread to the scrotum, inguinal region, or lower abdomen, then backwards to the perineum and anus. In the female it may spread into the vagina, backwards to the anal region, or forwards to the anterior abdominal wall.

The inguinal lesion tends to spread along the moist folds of the skin to the perineum or scrotum, and to join up with spreading lesions from the vulva or penis.

These later lesions retain the characteristics of the early lesion, and very extensive areas of the skin may be involved without marked pa'n or tenderness, regional adenitis, or disturbance of the general health (Fig. 1). The course is slow, chronic, and progressive; healing often takes place in one area while the lesion advances in another. Healed lesions are marked by formation of dense scar tissue, though these often break down with reformation of granulation tissue. New lesions also form where the granulomatous area makes contact with healthy skin on the scrotum or side of the thigh.

In clean, healthy, well-nourished subjects the granuloma is remarkably resistant to secondary infection, but in subjects debilitated by excesses (whether in venery or alcohol), undernourished, and unhygienic, the tissues may be invaded by other organisms, particularly spirochætes and fusiform bacilli. The picture then becomes that of a phagadenic ulcer with great tissue destruction, a foul smelling discharge, and constitutional symptoms (Fig. 4).

Hypertrophic lesions are sometimes seen (Fig. 3). Large vegetative masses spring from the lesion, forming a cauliflower-like growth. Esthiomenelike pictures are also seen (Fig. 6)-elephantiasis of the penis, scrotum, labiæ, and clitoris. (Elephantiasis of the clitoris appeared to be rather common 
in the Trinidad cases.) These result from obstruction of the lymphatic system by dense scar tissue and are independent of filariasis. Although genital elephantiasis is not uncommon in Trinidad; filariasis is very rare ; in fact local medical practitioners assert that there is no indigenous filariasis.

Extra-genital lesions are usually secondary to genital lesions and are seen in old, long-standing cases, probably the result of auto-inoculation. Cases, however, have been described unassociated with genital lesions, but these are uncommon.

Metastatic lesions have been described but are uncommon. None were seen in Trinidad.

Histology.-The remarkable feature about the histology is the exuberant overgrowth of the stratified squamous epithelium on the granulomatous surface. Though the surface looks raw and red, it is nevertheless covered by epithelium. This epithelium presents various abnormalities. The squamous cells are bloated and dropsical and contain vacuoles. Many of those in the surface layers contain bacteria. The basal layer becomes irregular and ill defined and the cells de-differentiated ; frequently it can scarcely be distinguished from the overlying prickle cell layer, and indeed the picture may suggest early neoplasia. The rete pegs are elongated and often form a lace-like network (Fig. 8), in the spaces of which is an exudate consisting of plasma cells with smaller numbers of polymorphonuclear cells, eosinophils, monocytes, fibroblasts, and an occasional lymphocyte. Occasionally small clumps of polymorphonuclear cells are found in these spaces, resembling miliary abscesses. There are many thin-walled capillaries which are frequently ruptured, producing small hæmorrhages. When proper staining methods are used, monocytes containing Donovan bodies can be found in the exudate, in the epithelial interstices, or in the superficial layers. Many may be packed with bodies-Greenblatt's pathognomonic cell.

Fibrocytes are conspicuous in the deeper parts of the lesion, and the older portions contain dense fibrous tissue.

In some areas the epithelial proliferation is suggestive of neoplasia even to the extent of pearl formation, yet it heals after specific treatment. Epithelial proliferation resembling neoplasia in the genital region in a young subject should raise a suspicion that the condition is granuloma inguinale.

Histologically the uncomplicated lesion is not an ulcerative process but a proliferative granuloma extending superficially in the skin and subcutaneous tissues. This was noted by some of the earlier observers. Conyers and Daniels (1896) say, "Though generally alluded to as an ulceration it is strictly speaking a new growth." Galloway (1897) refers to the lesion as a "tumour."

When secondary infection occurs the picture becomes more complicated and there is definite ulceration with destruction of tissue; nevertheless in biopsy sections the characteristic epithelial proliferation may be seen and Donovan bodies found.

Complications.-The commonest complication is secondary infection with pyogenic organisms. Neoplastic changes are not infrequently observed ; epidermoid carcinoma ip the ano-genital region in comparatively young subjects is not uncommon in Trinidad and is often associated with granuloma inguinale. In several of my cases, biopsy from one portion of the lesion revealed carcinoma and from another granuloma inguinale. The carcinoma may be squamous or basal-celled (Figs. 7, 8, 9, and 10). The change to malignancy is accompanied by increasing size of the regional lymph nodes, but malignancy is low and metastases are late in appearing.

Rectal stricture is not a complication. This is associated with lymphopathia venereum.

Diagnosis.-In uncomplicated cases the appearance and clinical picture are characteristic. The elevated, red, almost painless area of granulation tissue sharply demarcated from the surrounding skin ; the raised, rolled, smooth edge, not undermined ; the non-purulent serous or sero-sanguineous discharge; absence of regional adenitis even in the presence of extensive lesions, and the absence of constitutional disturbance form a characteristic picture not seen in any other condition.

Serological or other laboratory tests, apart from biopsy, are of little value. The disease is seen among the sexually promiscuous who have suffered from or are suffering from several venereal diseases. In Trinidad it was not uncommon to obtain reports of Kahn ++++ ; Frei test ++ ; Gonococci +++ from a patient with typical granuloma inguinale. Nevertheless all such tests must be performed, since all disease conditions present must be treated.

American workers base their diagnosis on the presence of Donovan bodies in smears or biopsy sections, mostly the former. The writer has found that the usual smear sent from a clinic is misleading as it is taken from the surface of the lesion. Cells clothing the surface contain intracellular bacteria of many varieties which may resemble Donovan bodies so closely as to deceive even the expert. Torpin and others (1939) recommend biopsy for diagnostic purposes as, they say, it is not infrequently 


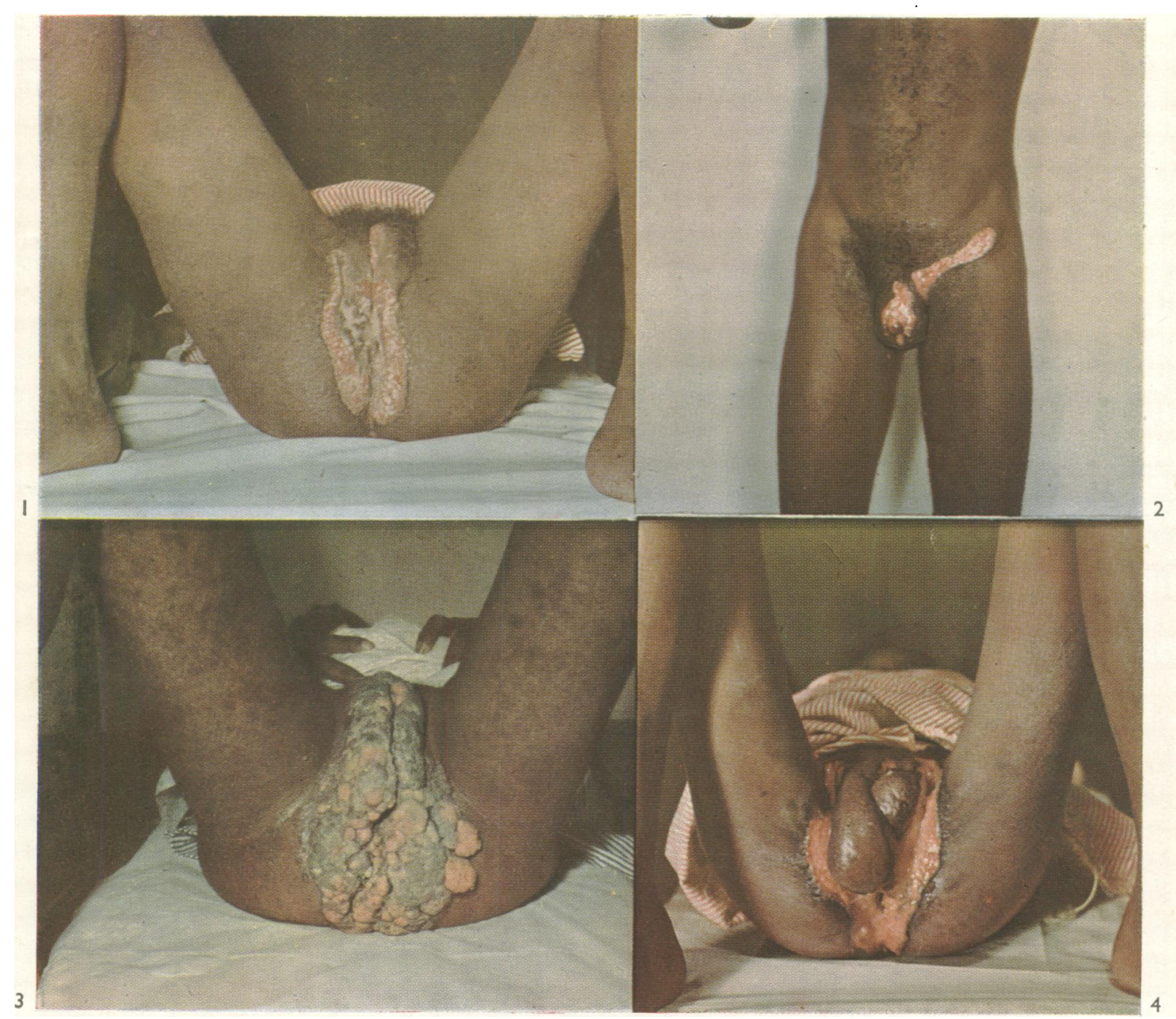

Fig. 1.-Granuloma inguinale in female extending from vulva to anus. The white spots are "sulpha" powder.

FIG. 2.-Granuloma inguinale on penis which has extended to the scrotum. Secondary lesion in inguinal region extending backwards between scrotum and thigh. The glistening white spots on the lesion are small patches of "sulpha" powder which it was impossible to remove before photographing without causing bleeding.

Fig. 3.-Proliferative lesion of granuloma inguinale in female.

FIG. 4.-Granuloma inguinale with secondary infection. Elephantiasis of labiæ. 
difficult to demonstrate Donovan bodies in smears because of marked contamination by other organisms. With this the writer is in complete agreement.

Even in biopsy material the bodies are difficult to demonstrate. Various stains have been described for the purpose, but most workers use one of the Romanowsky preparations, though some have

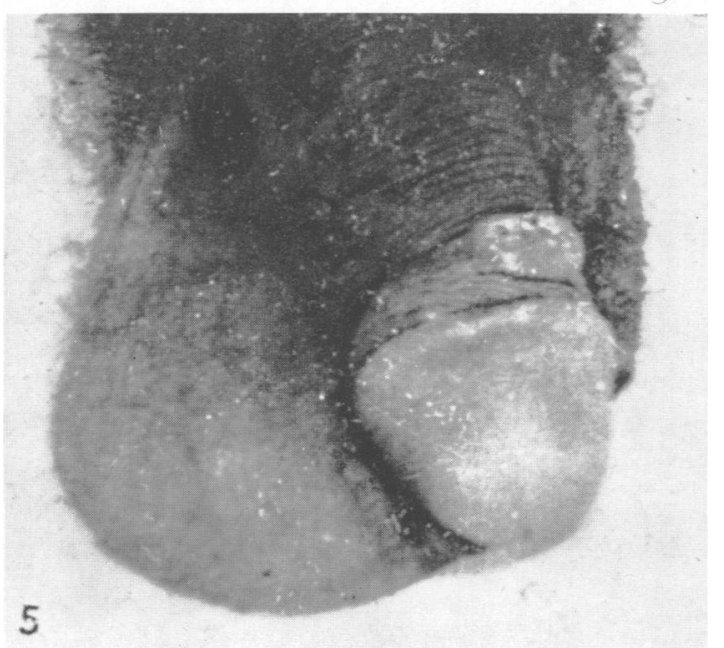

FIG. 5.- Early lesion of granuloma inguinale said to be of about four weeks' duration.

found it unsatisfactory. Polyase and Williams (1945) used hæmatoxylin and eosin successfully when other more elaborate methods, including Giemsa's stain, failed. Margolis (1945) found that Terry's polychrome methylene blue demonstrated the organism well in frozen sections when hæmatoxylin and eosin gave variable results. Pund and Greenblatt (1937) found Delafield's hæmatoxylin and eosin preferable to Giemsa for biopsy sections. Pariser and Beerman (1944) say that the organism is successfully stained by Delafield's hæmatoxylin and eosin, by Wright's or Giemsa's stain, or by silver impregnation (Dieterle), but they nevertheless describe a new technique for staining with analine blue and fuchsin, admitting that there is a " trick" about staining with Giemsa to demonstrate the organisms.

The writer tried many methods for staining smears and sections from the Trinidad cases. Silver impregnation was unsatisfactory as so many cell inclusions were stained. Hæmatoxylin and eosin were also unsatisfactory as only large forms were stained and they were so scanty that a complete section might have to be searched before one infected cell could be found. Giemsa's and Wright's stains failed, and it was only on return to this country that the organisms were demonstrated satisfactorily with another brand of Giemsa's stain (Gurr's R 60). It would appear that the difficulty often encountered by many workers in demonstrating Donovan bodies may be attributed to an unsatisfactory brand of Giemsa's stain.

Good optical equipment correctly centred, good lighting, and adequate magnification are also essential. Sections should be thin, well stained, mounted in Gurr's neutral mounting medium, and examined with the $1 / 12$ inch oil immersion lens with No. 4 ocular.

The unskilled observer can easily mistake other inclusions for Donovan bodies, especially if staining is not satisfactory and the optical equipment or lighting poor.

Differential Diagnosis.-Chancroid should not be mistaken for granuloma inguinale if the latter is uncomplicated by secondary infection. The course of the former is rapid and painful with marked constitutional symptoms; the latter is slow and chronic, almost painless, and free from constitutional disturbance. One is a frank ulceration with tissue destruction, ragged, undermined edges, and foul purulent discharge ; the other is a raised granuloma with no tissue destruction, smooth rounded edges, and serous discharge.

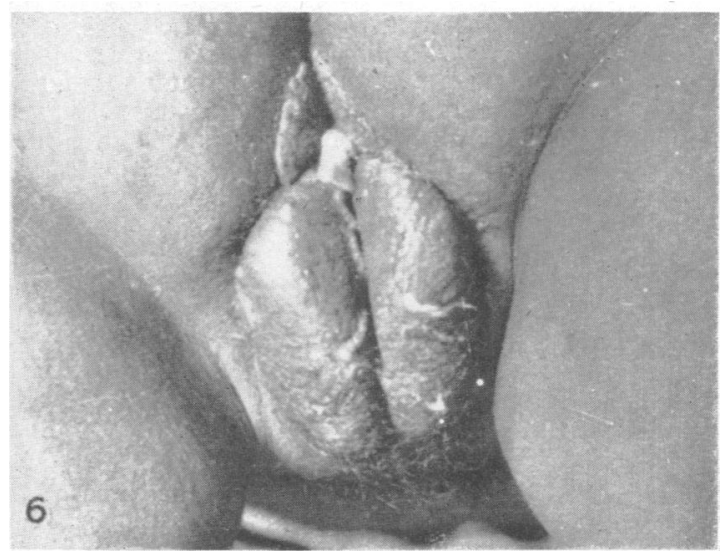

FIG. 6.-Granuloma inguinale in female with elephantiasis of vulva. The granulomatous area can be seen below, extending in the direction of the anus.

Lymphopathia venereum should be excluded without difficulty-not by the Frei test but by the clinical appearance. In lymphopathia venereum the inguinal lymph nodes swell, rupture, and form ragged ulcers and sinuses in the inguinal region (Fig. 11).

Tuberculosis and carcinoma are excluded by biopsy and histological examination. 


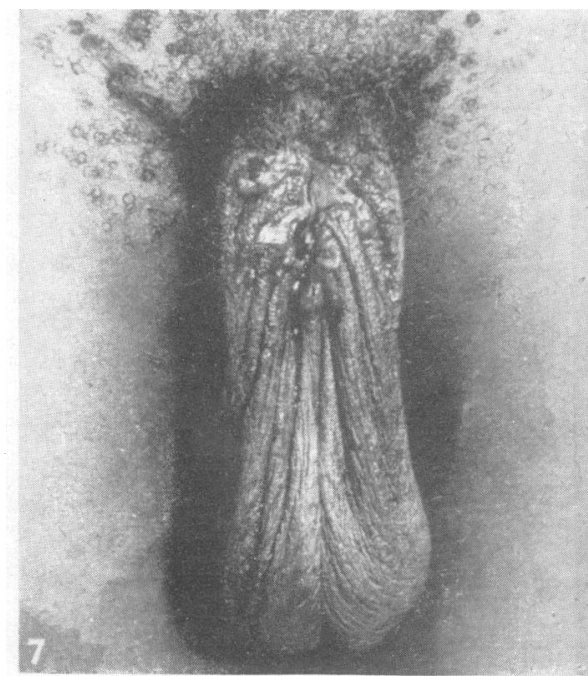

FIG. 7.-Granuloma inguinale in male which became carcinomatous necessitating amputation of the penis. This was followed by recurrence of the granuloma on the scrotum around the uretheral orifice which also underwent a carcinomatous change. See next two figures.

FIG. 8.-Photomicrograph of a section from the lesion in Fig. 7, showing characteristic histological picture of granuloma inguinale.

FIG. 9.-Section from another area of the same lesion, showing histological carcinoma.

FIG. 10.- Section from another case of granuloma inguinale showing carcinomatous change.

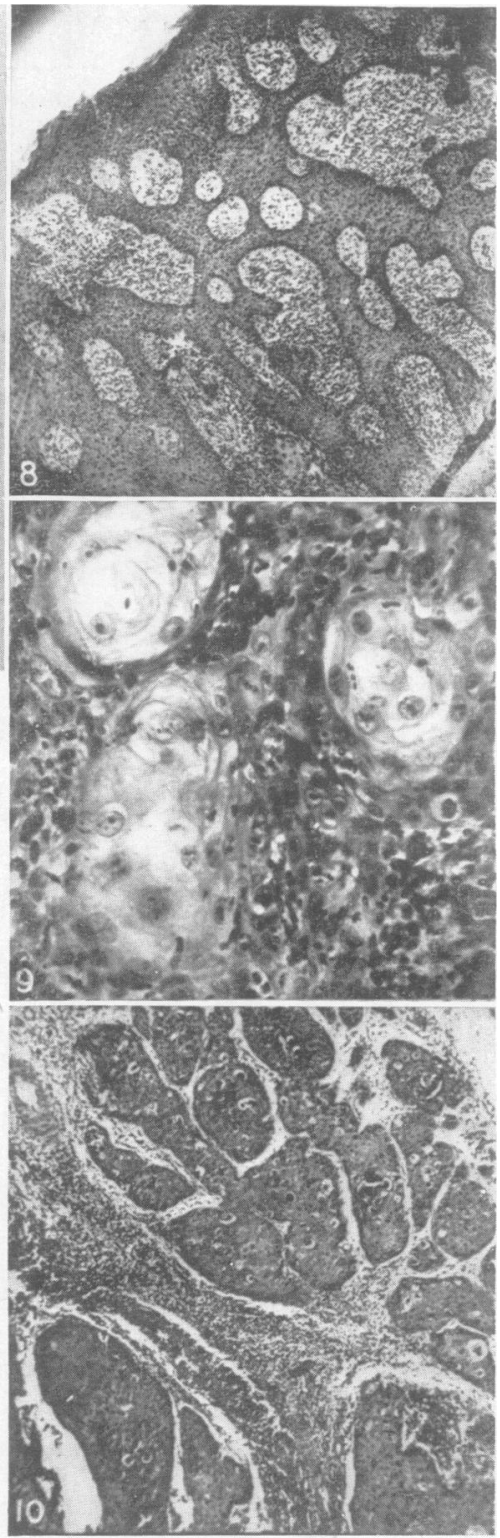



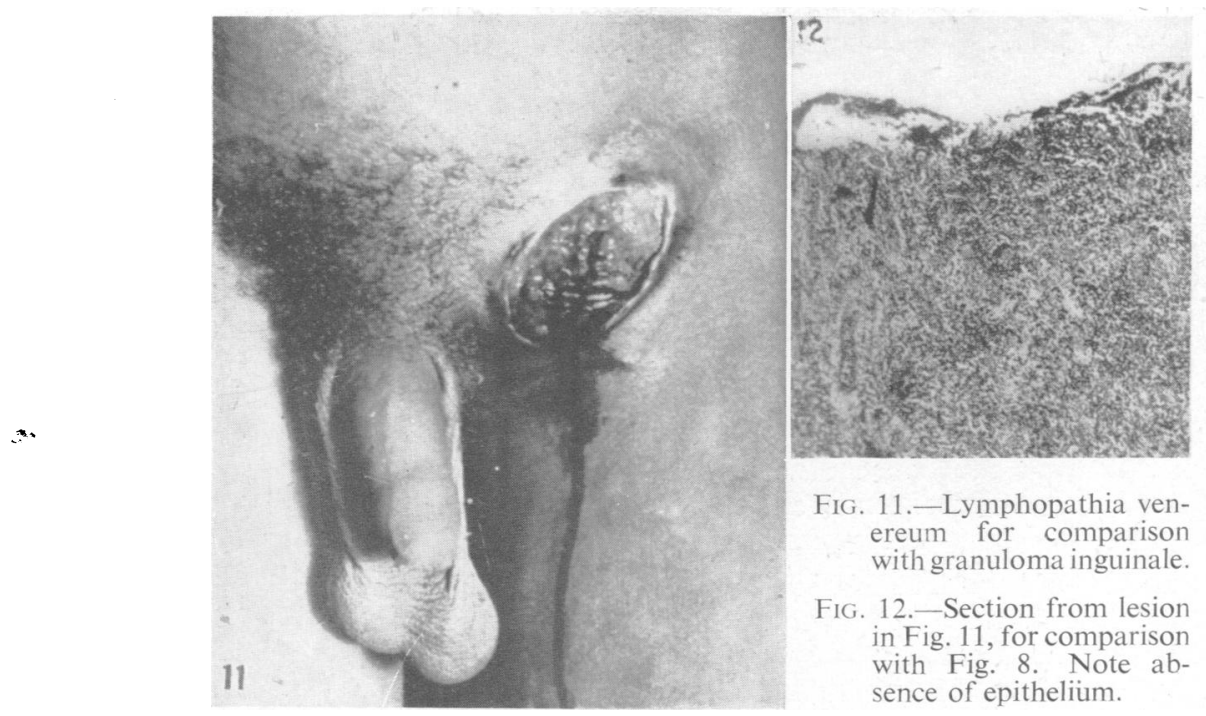

Treatment

General health must first receive attention and any concurrent disease such as syphilis or gonorrhœa obtain appropriate treatment. The arsenicals, sulpha drugs, and penicillin have no effect on granuloma inguinale but specific treatment of this disease is not effective until the other diseases are controlled. Secondary infection should be treated in the usual way by surgical cleanliness and sulpha drugs or penicillin. Beveridge (1946) confirmed Greenblatt's observation that there may be no response to specific treatment in the presence of secondary infection. It is advisable, therefore, to treat the secondary infection before commencing specific treatment.

Antimony is specific. Beveridge (1946) showed that trivalent compounds are more bacteriostatic than pentavalent on Donovan bodies in vitro, thus confirming clinical observations.

Tartar emetic in one per cent. solution was formerly used but has been abandoned in favour of one of the modern preparations of antimony. Fuadin has proved satisfactory. A preliminary dose of two to three c.cm. should be given to ascertain if the patient is unduly sensitive to the drug. If no reaction follows, $5 \mathrm{c} . \mathrm{cm}$. may be given by intramuscular injection three times a week and continued until the lesions have completely healed for two months. As this may necessitate many months of treatment it is advisable to cease treatment periodically for one week. Improvement should appear after three or four weeks' treatment. Relapse is common, and relapses should be similarly treated.
Anthiomaline and stibophen have proved equally satisfactory and should be used in the same manner as Fuadin. If one preparation fails to effect a cure, one of the others may be more successful.

Streptomycin has given promising results. Marshak and Rodriquez (1948) treated eleven cases with doses varying from $3.4 \mathrm{~g}$. to $12.6 \mathrm{~g}$. administered over a period of eighteen to forty-one days. Though all healed, three relapsed afterwards, probably due to insufficient doses of streptomycin. The relapsed cases responded to further treatment with streptomycin or antimony, and they showed no sign of relapse when inspected from two to fifteen months later.

\section{Prognosis}

The earlier a case is diagnosed and treated the better the prognosis. Old, long-standing cases respond badly to all treatment, and recurrence is frequent. Such cases often develop malignant changes, become anæmic, cachectic, and die.

\section{REFERENCES}

Anderson, Katherine (1943). Science, 97, 560.

Beveridge, W. L. B. (1946). J. Immunol., 53, 215.

Campbell, M. F. (1921). J. Amer. med. Ass., 76, 648.

Carter, R. M. (1910). Lancet, 2, 1128.

Castellani, A., and Mendelson, R. W. (1929). J. Trop. Med. Hyg., 32, 148.

Clearkin, P. A., and Flewett, T. H. (1948). Paper read before the Society of Pathology and Bacteriology of Great Britain and Ireland. Summer meeting, 1948.

Conyers, J. H., and Daniels, C. W. (1896). Brit. Guiana med. Ann., p. 13.

Daniels, C. W. (1910). Lancet, 2, 1648.

D'Aunoy, R., and von Haam, E. (1937). Amer. J

Path., 13, 651. I Ibid., 14, 39. 
Dienst, R. B., Greenblatt, R. B., and Sanderson, E. S. Pariser, H., and Beerman, H. (1944). Amer. J. med. (1938). J. infect. Dis., 62, 112 .

Donovan, C. (1905). Ind. med. Gaz., 40, 414.

Fowler, J. F. S. (1899). Brit. Guiana med. Ann., p. 22.

Galloway, J. (1897). Brit. J. Derm., 9, 133.

Goldzieher, M., and Peck, S. M. (1926). Virchow's Arch., 259, 795.

Greenblatt, R. B. (1943). Vener. Dis. Inform., Suppl. 19.

Grindon, J. (1913). J. Cutan. Dis., 31, 236.

Lynch, K. M. (1921). J. Amer. med. Ass., 77, 925.

McLeod, K. (1882). Ind. med. Gaz., 17, 113.

Margolis, G. (1945). Amer. J. Path., 21, 543.

Marshak, Lydia C., and Rodriquez, J. (1948). J. Amer. med. Ass., 137, 1293.

Ozzard and Neal (1893). Brit. Guiana med. Ann., p. 137.

Sci., $208,547$.

Polayes, S. H., and Williams, L. (1945). Amer. J. Syph., $29,425$.

Pund, E. R., and Greenblatt, R. B. (1937). Arch. Path., 23, 224.

Rake, G., and Oskay, J. J. (1948). J. Bact., 55, 667.

Rake, G. (1948). Ibid., 55, 865.

Sequeira, J. H. (1908), Proc. R. Soc. Med., 1, Part 1, Section A, Dermatology, p. 57.

Sequeira, J. H. (1908). Ibid., p.92.

Sidlick, D. M. (1927). Arch. Derm. Syph. Chicago, 15. 703.

Torpin, R., Greenblatt, R. B., and Pund, E. R. (1939). Amer. J. Surg., 44, 551. 